\title{
Effects of Mulching with Tolerant Plants Straws on Soil Nutrients under Cadmium Stress of Cyphomandra betacea Seedlings
}

\author{
Kewen Huang1,a, Liying Ouyang ${ }^{2, b}$, Ming'an Liao ${ }^{1, \mathrm{c}}$ and Lijin Lin ${ }^{3, \mathrm{~d} *}$ \\ ${ }^{1}$ College of Horticulture, Sichuan Agricultural University, Chengdu, Sichuan, China \\ ${ }^{2}$ Department of Modern Agriculture, Chendu Agricultural College, Chengdu, Sichuan, China \\ ${ }^{3}$ Institute of Pomology and Olericulture, Sichuan Agricultural University, Chengdu, Sichuan, China \\ a263733029@qq.com, b24983471@qq.com, Iman@sicau.edu.cn, dllj800924@qq.com \\ ${ }^{*}$ Corresponding author. Kewen Huang and Liying Ouyang contributed equally to this work.
}

Keywords: Cyphomandra betacea; Tolerant plant straw; Soil nutrients content; Cadmium stress

\begin{abstract}
A pot experiment was carried out to study effects of planting Cyphomandra betacea seedlings after mulching with four tolerant plants straws (Digitaria sanguinalis, Clinopodium confine, Plantago asiatica and Ranunculus sieboldii) on soil nutrients under cadmium stress. The results showed that all tolerant plants straws could improve the content of soil nutrients in varying degrees. And the content of alkaline nitrogen, available phosphorus, available potassium and organic matter in cadmium contaminated soil was highest among all treatments by mulching with $P$. asiatica straw. Therefore, planting $C$. betacea seedlings after mulching with $P$. asiatica straw in cadmium contaminated soil could effectively increase soil available nutrients content.
\end{abstract}

\section{Introduction}

Due to the rapid development of industry and agriculture, soil contamination by cadmium (Cd) has become more and more serious [1]. Cd is prone to long-term accumulation in the soil, which can directly affect the effectiveness of nutrients in the soil by changing the physical and chemical properties of the soil [2]. And under Cd stress, not only the plant will be poisoned, but also accumulated in the human body through the food chain for a long time [3]. Study has shown that returning straw to soil can improve soil structure and nutrients cycling, and at the same time it has a significant effect on improving the effectiveness of soil nutrients [4]. It has been found that mulching with straw, corn straw and bagasse in Cd-contaminated tea gardens could effectively increase the content of organic matter, available phosphorus, available potassium and alkaline nitrogen in different soil layers, thereby improving the quality and yield of tea [5]. The Cyphomandra betacea is a perennial evergreen shrub of the genus Solanaceae, which is rich in nutrients, sweet, and has high ornamental and edible value [6]. But with the intensification of $\mathrm{Cd}$ pollution in orchards, the quality and yield of $C$. betacea has been affected. Predecessor has studied that planted $C$. betacea seedlings after mulching with four tolerant plants straws: Digitaria sanguinalis, Clinopodium confine, Plantago asiatica, Ranunculus sieboldii in Cd-contaminated soil can effectively increase $C$. betacea photosynthetic pigment content, antioxidant enzyme activity and significantly promote the growth of $C$. betacea [7]. However, the effects of planting $C$. betacea seedlings on soil nutrients content after mulching with these four tolerant plants straws have not been reported. Therefore, this study investigated the effects of planting $C$. betacea seedlings after mulching with $D$. sanguinalis, $C$. confine, $P$. asiatica and $R$. sieboldii straws on the content of alkaline nitrogen, available phosphorus, available potassium and organic matter in Cd-contaminated soil.

\section{Materials and Methods}

Materials Collection. The shoots of four tolerant plants (D. sanguinalis, C. confine, $P$. asiatica, $R$. sieboldii) and soil were collected from the farmland of Ya'an Campus of Sichuan Agricultural University (not polluted by Cd) in June, 2014. And fixed all plants at $110^{\circ} \mathrm{C}$ for 15 minutes and 
dried at $80^{\circ} \mathrm{C}$ until they were weighed after washing them with deionized water. Then cut into small pieces of less than $1 \mathrm{~cm}$ by scissors and stored. The seeds of $C$. betacea were collected from three-years of fruitful $C$. betacea from the Ya'an Campus of Sichuan Agricultural University in October 2013. And the seeds of C. betacea were sowed in the sand plate in June 2014.

Experimental Design. The experiment was conducted in farm of Ya'an Campus of Sichuan Agricultural University. In June 2014, the unpolluted soil was air-dried and passed through a 5-mm sieve. $3 \mathrm{~kg}$ air-dried soil was weighed into each plastic pot $(15 \mathrm{~cm}$ high, $18 \mathrm{~cm}$ in diameter), soaking uniformly CdCl $2 \cdot 2.5 \mathrm{H} 2 \mathrm{O}$ by $10 \mathrm{mg} / \mathrm{kg}$ and balanced for 4 weeks. In July 2014, the straws of four tolerant plants were separately mulched in Cd-contaminated soil surface. Coverage was $6 \mathrm{~g}$ per pot and the water was kept moist and equilibrated for one week. Then, the same growth $C$. betacea with the four real leaves were transplanted into the pots. Two plants were planted in each pot. Five replicates per treatment and all pots were watered each day to keep the soil moisture about $80 \%$. The distance between pots was $15 \mathrm{~cm}$, and the pot position exchanged aperiodically to weaken the impact of the marginal effects. After 40 days, the soil near the roots of $C$. betacea seedlings was collected and naturally air-dried, and then passed over a $1 \mathrm{~mm}$ nylon screen respectively. The measurement of alkaline nitrogen, available phosphorus, available potassium and organic matter content in soil refers to the method of Bao [8].

Statistical Analyses. Statistical analyses were conducted using statistical software of SPSS 17.0. Data were analyzed by one-way ANOVA with least significant difference at 5\% confidence level.

\section{Results and Discussion}

Alkaline Nitrogen Content in Soil. For the content of soil alkaline nitrogen, compared to uncovered, mulching with $D$. sanguinalis, $C$. confine and $R$. sieboldii straws had no significant effects on the content of alkaline nitrogen in soil (Fig. 1). Only mulching with $P$. asiatica straw significantly increased the alkaline nitrogen content in soil compared with the uncovered $(P<0.05)$.

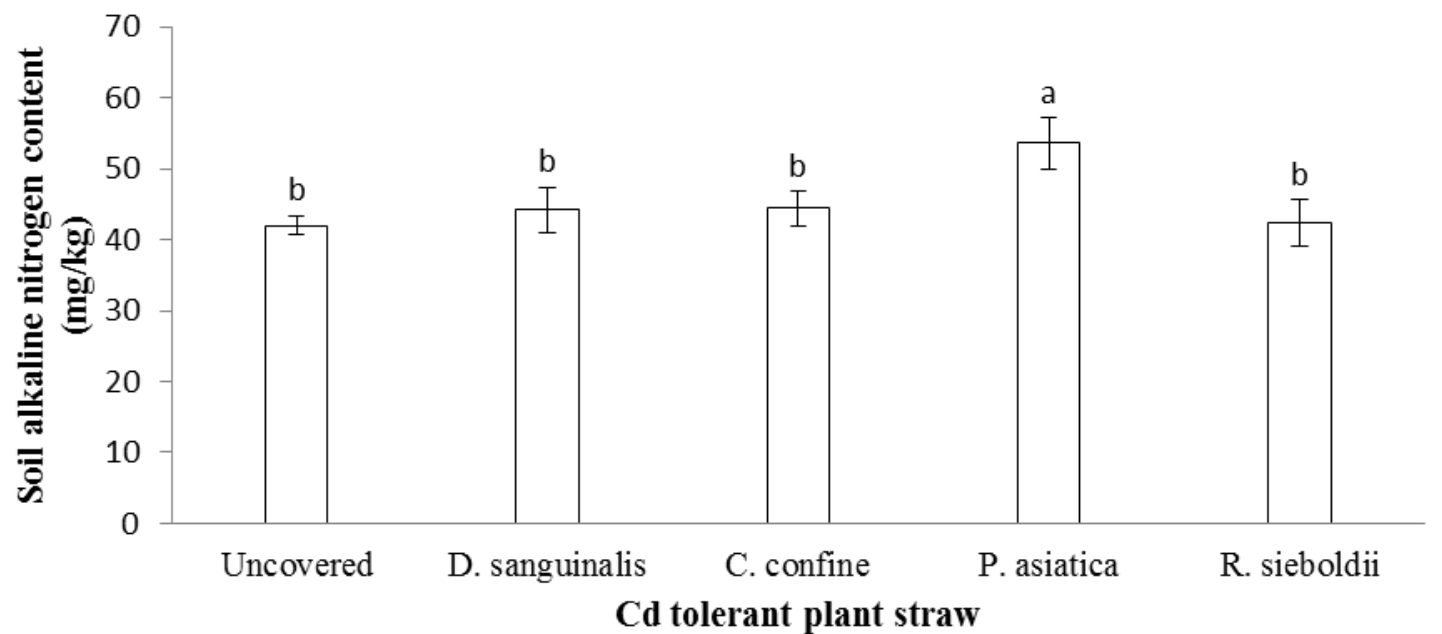

Fig. 1 Alkaline nitrogen content in soil

Means with the same letter within each column are not significantly different at $p<0.05$.

Available Phosphorus Content in Soil. For the content of soil available phosphorus, the order from large to small was ranked: P. asiatica, $C$. confine, $R$. sieboldii, D. sanguinalis, uncovered (Fig. $2)$. Compared to uncovered, mulching with $P$. asiatica, $C$. confine and $R$. sieboldii straws significantly increased the content of available phosphorus in soil $(P<0.05)$. And mulching with $D$. sanguinalis straw had no significant effect on the content of soil alkaline nitrogen compared with the uncovered.

Available Potassium Content in Soil. Compared to uncovered, mulching with tolerant plants 
straws could significantly increase the content of available potassium in soil $(P<0.05)$. And the order of soil available potassium content from large to small was ranked: $P$. asiatica, $C$. confine, $R$. sieboldii, D. sanguinalis, uncovered (Fig. 3). Among all treatments, the content of soil available potassium was highest by mulching with $P$. asiatica straw.

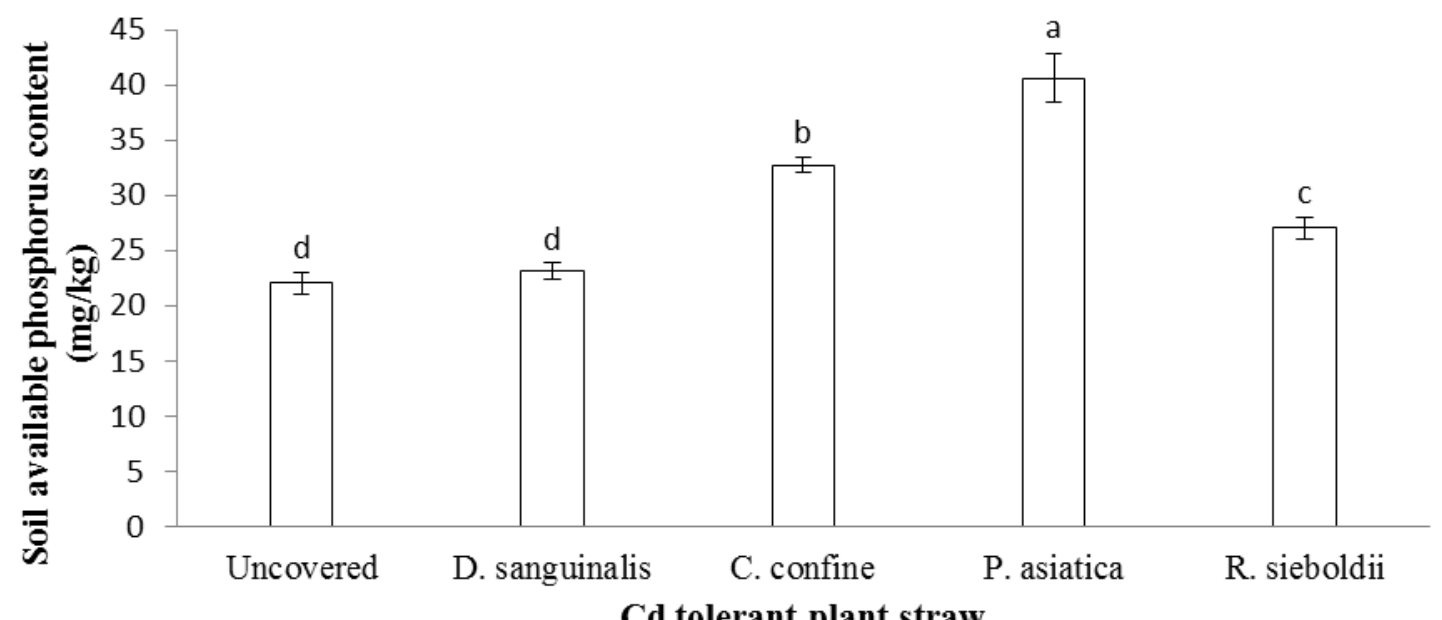

Fig. 2 Available phosphorus content in soil

Means with the same letter within each column are not significantly different at $p<0.05$.

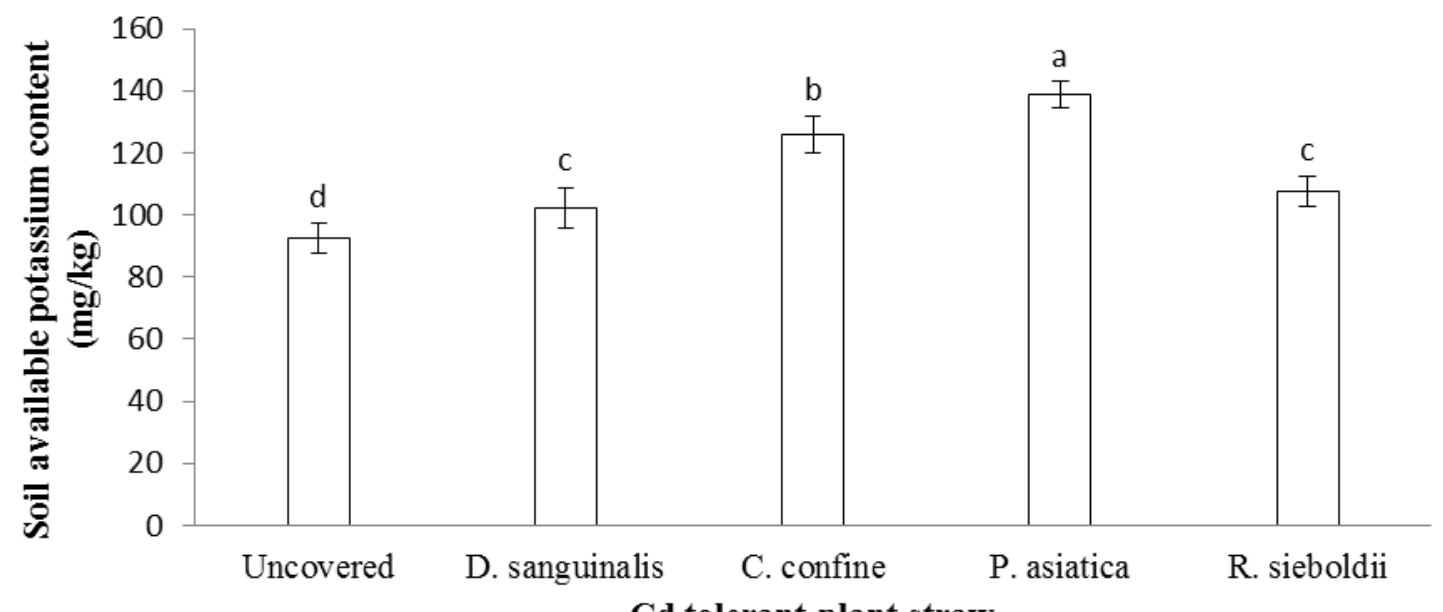

Cd tolerant plant straw

Fig. 3 Available potassium content in soil

Means with the same letter within each column are not significantly different at $p<0.05$.

Organic Matter Content in Soil. For the content of soil organic matter, mulching with tolerant plants straws could significantly increase the content of organic matter in soil $(P<0.05)$. The order of soil organic matter content from large to small was ranked: P. asiatica, C. confine, D. sanguinalis, $R$. sieboldii, uncovered (Figure 4). The organic matter content in soil was highest in all treatments by mulching with $P$. asiatica straw (Fig. 4).

\section{Conclusions}

In cadmium contaminated soil, planting $C$. betacea after mulching with $D$. sanguinalis, $C$. confine, $P$. asiatica and $R$. sieboldii straws could improve the content of available nutrients in soil. Compared to uncovered, the content of alkaline nitrogen, available phosphorus, available potassium and organic matter in soil was significantly higher than other treatments by mulching with $P$. 
asiatica straw. These results indicated that planting $C$. betacea after mulching with $P$. asiatica could effectively increase the content of available nutrients in soil.

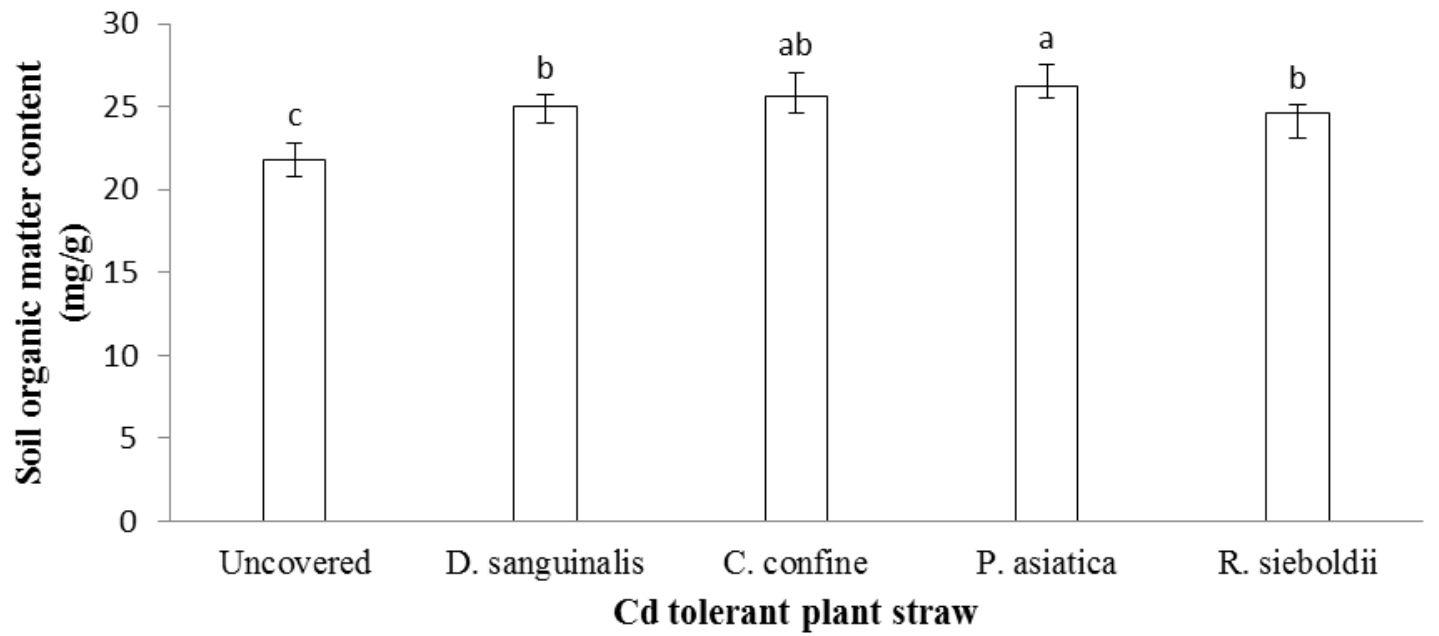

Fig. 4 Organic matter content in soil

Means with the same letter within each column are not significantly different at $p<0.05$.

\section{Acknowledgements}

This work was financially supported by the Application Infrastructure Project of Science and Technology Department of Sichuan Province (2016JY0258).

\section{References}

[1] Y.S. Xia, K.R. Wang and G.L. Zhang: Agro-environmental Protection Vol. 21(2002), p. 272.

[2] Z.M. Dou, F. Ding, X.X. Li, D.H. Cheng and S.Q. Wang: Hunan Agricultural Sciences Vol. 5(2012), p. 53.

[3] Y.H. Xiong and X.E. Yang: Journal of Anhui Agri. Sci. Vol. 34(2006), p. 2969.

[4] P.J.A.V. Asten, P.M.V. Bodegom, L.M. Mulder and M.J. Kropff: Nutrient Cycling in Agroecosystems Vol. 72(2005), p. 255.

[5] L.Q. Yin, Z.M. Shi, J. Liu, Z.W. Luo, D.H. Liu, Q.X. Luo, Z.F. Duan, R. Xia and X. Xiao: Journal of Southern Agriculture Vol. 44(2013), p. 1483.

[6] B.G. Yu, L. Qin, F.D. Zhan, Y.Q. Zu, B. Li, J.X. Wang and Y. Li: Journal of Agro-Environment Science Vol. 37(2018), p. 621.

[7] J. He, L.J. Lin, J, Shi, Y.M. Tan, Q.Q. Ma, C.Y. Liu, K. Wen, J.J. Huang, C.C. Zhong and M.A. Liao: Chinese Journal of Soil Science Vol. 47(2016), p. 1259.

[8] S.D. Bao: Agrochemical Soil Analysis (3rd edition, China Agriculture Press, Beijing, China 2000). 